\title{
ROLE OF TIME STUDY IN EMERGENCY DEPARTMENT OF AN INDIAN HOSPITAL FOR QUALITY HEALTH CARE
}

\author{
KHEKALE SN ${ }^{1}$, ASKHEDKAR RD ${ }^{2}$, PARIKH RH ${ }^{3}$, DEVESH D GOSAVI ${ }^{4}$ \\ ${ }^{1}$ Asistant Professor, Department of Mechanical Engineering GH Raisoni Academy of Engineering and Technology, Nagpur. ${ }^{2}$ Ex -Pricipal, \\ K.D.K.College of Engineering, Nagpur, Maharashtra, India. ${ }^{3}$ Professor, Mechanical Engeering K.D.K.College of Engineering, Nagpur, \\ Maharashtra, India. ${ }^{4}$ Department of Pharmacology, MGIMS, Wardha, Maharashtra, India. Email: deveshgosavi@gmail.com
}

Received: 23 October 2016, Revised and Accepted: 06 October 2016

ABSTRACT

Objectives: To study the role of time study in the emergency department (ED) of an Indian hospital for quality health care. For that, an observational cross-sectional time study was conducted at the casualty department of largest hospitals situated at central India.

Methods: Systemic random sampling method is used to select the patients attending the ED. Following parameters and procedure were observed during time study in the casualty department. Patient shifting on bed in ED, patient attending by nursing staff, patient attending and treatment by casualty medical officer (CMO), waiting time for intensivist, diagnostic procedure, waiting time for bed and after the availability of bed, patient was shifted to Intensive Coronary Care Unit (ICCU)/Intensive Care Unit (ICU)/ward.

Results: Waiting times are observed which are of five types such as waiting for ward boy, CMO, intensivist, diagnostic procedure, and for bed in ICCU or ICU or ward.

Conclusion: Result of this time and motion study shows that after the entry of the patient in the ED, he or she is subjected to different kinds of waits like for ward boy, intensivist, diagnostic tests, bed in ICCU or ICU or ward. Out of this, wait for intensivist and for bed are very important for the overall treatment of the patient. The hospital should aim at reducing these waits by proper management. This study focuses scope for the improvements in patient waiting time which is the important contributor of the patient satisfaction.

Keywords: Time study, Motion study, Waiting line model.

(c) 2017 The Authors. Published by Innovare Academic Sciences Pvt Ltd. This is an open access article under the CC BY license (http://creativecommons. org/licenses/by/4. 0/) DOI: http://dx.doi.org/10.22159/ajpcr.2017.v10i1.9616

\section{INTRODUCTION}

The role of emergency department (ED) in multi spatiality hospital is to provide timely health-care service to the patients. To provide speedy service, there should be availability of every resource on time. Every step should be completed within standard time. To understand the distribution of time for various steps, time study is required. The ED thus needs a systematic analysis of its services consisting procedure for its efficient management and function. It is, therefore, very important that a simple time and motion study of casualty department system is needed for achieving further improvement.

Time and method study are two parts of techniques constituting the work study. Work study may be defined as the systematic examination of existing methods of carrying on activities to improve the effective use of manpower and equipment and to set up standards of performance for the activities being performed. Method study is the systematic recording and critical examination of the existing ways of doing things to make improvements. It involves investigation of existing or alternates proposed methods of work and improving them. Time study, which is also called as work measurement, is application of systematic techniques to establishing time standards for carrying out specified jobs. It estimates how long a job should take and the manpower and equipment requirements for a given method. It also helps to find out what are the value-added activities and non-value-added activities. The activities that change the size, shape, fit, form, or function of material or information (for the first time) to satisfy the customer and for which customers are willing to pay are called as value added activities. Those activities that consume time or resources but do not add value in the eyes of the customer and for which customers are not willing to pay are called as non-value-added activities.
Kyriacou et al. [1] showed that time study was an effective method of identifying areas of patient care delay in ED, and pointed administrative interventions which reduced the total length of stay (LOS) of the patient and improved overall efficiency.

Time and motion study conducted by Hendrich et al. [2] in an ED identified three subcategories of nursing service time as for documentation, medication administration, and care coordination.

Saunders conducted a continuous observation time study and found delay, especially in different laboratory tests, and blood tests and had an increasing impact on treatment times which were the frequent sources of patient dissatisfaction [3].

A study was done by Huang et al. and determined the impact of delay in admission from the ED on inpatient LOS [4].

Time and motion study was conducted by Worster et al. identified 3 root causes of delay (a processing of radiograph request order by registered nurse, transport times, and radiology suite location [5].

Qian et al. [6] applied time motion study and explained the work pattern of personal care workers in nursing homes in following terms: Activity time, frequency, duration, and the change in between two consecutive activities.

Gottschalk and Flocke [7] conducted time motion study and documented how physicians spend time during the workday, including time outside the examination room, and compared observed direct patient care time with that reported in the National Ambulatory Medical Care Survey. 
Similar studies were carried out and important parameters found by ED time study are as follows,

a. Time for documentation and conversation with colleagues and nursing staff [8].

b. Waiting time with respect time required to be seen by nursing staff and doctor [9].

c. Waiting time for patients of lesser priority for assessment by staff, waiting time for laboratory and imaging investigations [10].

d. Waiting times for laboratory results, triage, and seeing a doctor, particularly for older medicine patients [11]

e. Length of stay for the critically ill patients and noncritically ill patients [12].

Such type of literature on time and motion study in Indian set up is lacking. Hence, we decided to conduct randomized observational crosssectional time study in the casualty department of multi spatiality hospital located in central India over a period of 6 months.

\section{METHODS}

We designed randomized observational cross-sectional time study in the ED of multi spatiality hospital located in central India over a period of 6 months.

Ethical permission was taken from hospital authority. Sample size was calculated from the standard formula. Total 360 patients were observed in the casualty department from their entry in casualty department to shifting to Intensive Coronary Care Unit (ICCU)/Intensive Care Unit (ICU)/ward.

Following parameters and procedure were observed during time study in the casualty department.

1. Patient shifting on bed in ED

Shifting of the patient from ambulance or vehicle to stretcher if wad boy was available on time. This stretcher was carried to ED, and the patient was shifted on bed in ED.

2. Patient attending by nursing staff Patient attending by nursing staff carried dressing of the injuries, measured the blood pressure and checked the pulse rate of the patient, and reported to casualty medical officer (CMO).

3. Patient attending and treatment by CMO

CMO completed a physical examination of the patients such as checking the vital signs and gave the instructions to nursing staff for electrocardiogram, IV, and injections. Simultaneously CMO took the previous history of the patient. Thus, according to the patient's condition, initial treatment was given to the patient by the CMO. If the condition of the patient was serious, then CMO made contact by telephone call to the intensivist and shortly explained the position of the serious patient.

4. Waiting time for intensivist

As the intensivist was not arrived on time, the patient had to wait at the casualty department, intensivist arrived and examined the patient. Then, he gave necessary direction to the CMO about X-ray, pathological tests, computed tomography (CT) scan according to the severity of the patient.

5. Diagnostic procedure

After the necessity of diagnostic tests for patients, nursing staff checked the availability for the same. After the availability in the diagnostic center, nursing staff shifted the patient from the bed on the stretcher. Ward boy along with nurse moved the patient to the diagnostic center.

6. Waiting time for bed

After the diagnostic procedure, nursing staff checked the availability of bed in the ICCU by contacting the personal relation officer by telephone. The patient was shifted to casualty department if the ward was not available.

7. After the availability of bed, the patient was shifted to ICCU/ICU/ ward

All above activities were included in time study sheet so that time required for every small activity could be recorded
Thus, this time study sheet was developed to record time accurately for every activity which is explained above and given in time study sheet (Table 1).

Patients entering the casualty department were categorized according to their severity as given below:

Level I (Resuscitation): Conditions of the patient that are life threatening or imminent risk of worsening, requiring immediate aggressive interventions (e.g., cardiac arrest, major trauma or shock states, severe head injury).

Level II (Emergent): Conditions of the patient that are potential threat to life or limb function requiring rapid medical intervention or delegated acts (e.g., chest pain, gastrointestinal bleeding, abdominal pain with visceral symptoms, and neonates with hyperbilirubinemia). Level III (Less urgent): Conditions of the patient that could potentially progress to a serious problem requiring emergency intervention (e.g. ,mild-moderate asthma or dyspnea, moderate trauma, vomiting and diarrhea in patients younger than age 2). Conditions related to patient age, distress or potential for deterioration or complications that would benefit from intervention or reassurance within 1-2 hrs (e.g., urinary symptoms, mild abdominal pain, and earache).

\section{RESULTS}

From time study, different waiting times were observed which are of five types such as:

- Waiting for ward boy,

- CMO,

- Intensivist

- Diagnostic procedure and

- For bed in ICCU or ICU or ward

Waiting time for intensivist and for bed in ICCU/ICU/ward are of having high value for the patients of priority Levels I, II, and III. For patients of priority Levels I and II, time is very important.

For priority-I patients, every second is very important, and it is most important to provide such patients timely service without wait. Extra time consumption will lead to many problems to the patient and finally death also.

With the help of this time study, we to drew detailed patient flow diagram from patient arrival to patient shifted to ICU/ICCU/ward. This was the most important result as to get this flow chart which is as follows (Fig. 1).

Findings of time study sheet are described below:

- $\quad 1^{\text {st }}$ activity was waiting for ward boy, which occurred sometimes due to non-availability of ward boy.

- $\quad 2^{\text {nd }}$ activity included shifting the patient from ambulance to bed in the casualty department. After shifting of the patient on bed, nursing staff responded to the patient as per $3^{\text {rd }}$ step. There was not any waiting time for nursing staff. In general, nursing staff was used to respond the patient arrived in casualty department ( $4^{\text {th }}$ step). Therefore, time to start treatment by CMO was introduced as waiting for time ( $5^{\text {th }}$ step) for CMO.

After contacting the intensivist about severity of patient, intensivist was not readily available as he was also involved in another important work or in the other hospital. The patient had to wait for some minutes for intensivist as per $6^{\text {th }}$ step. After arrival, intensivist gave the treatment to the patient as in $7^{\text {th }}$ step. After starting treatment by intensivist if diagnostic tests were required, patient had to be sent to diagnostic center ( $8^{\text {th }}$ step). For that availability of diagnostic center was checked by nursing staff. If the diagnostic center was not available patient had to wait for that in the casualty department ( $9^{\text {th }}$ step). After diagnostic tests, the patient had to shift to ICCU/ICU/ward as per availability of the bed $\left(13^{\text {th }}\right.$ step). However, if bed was not available, the patient had to wait for some minutes in the casualty bed ( $12^{\text {th }}$ step). 
Table 1: Time study sheet

\begin{tabular}{|c|c|c|c|c|c|c|}
\hline S. No. & Name of activity & $\begin{array}{l}\text { Patient } \\
\text { No. } 1\end{array}$ & $\begin{array}{l}\text { Patient } \\
\text { No. } 2\end{array}$ & $\begin{array}{l}\text { Patient } \\
\text { No. } 3\end{array}$ & $\begin{array}{l}\text { Patient } \\
\text { No. } 4\end{array}$ & $\begin{array}{l}\text { Patient } \\
\text { No. } 5\end{array}$ \\
\hline 1. & Waiting time for availability of ward boy (Wt-1) & & & & & \\
\hline 2. & Patient shifting on the bed & & & & & \\
\hline 3. & Patient attending by the nursing staff & & & & & \\
\hline 4. & $\begin{array}{l}\text { Time for attending and } \\
\text { checking of patient by } \\
\text { Casualty medical officer (Wt-2) }\end{array}$ & & & & & \\
\hline 6. & Waiting time for availability of intensivist (Wt-3) & & & & & \\
\hline 7. & Checking and treating of patient by the & & & & & \\
\hline 8. & Waiting time for diagnostic procedure (Wt-4) & & & & & \\
\hline 9. & Shifting of patient to diagnostic center & & & & & \\
\hline 10. & Tests at diagnostic center & & & & & \\
\hline 11. & Shifting of patient to emergency department & & & & & \\
\hline 12. & $\begin{array}{l}\text { Waiting time for availability of bed in ICCU/ICU/ } \\
\text { ward (Wt-5) }\end{array}$ & & & & & \\
\hline \multirow{3}{*}{13.} & Total service time & & & & & \\
\hline & Total wait time & & & & & \\
\hline & Total time & & & & & \\
\hline
\end{tabular}

\section{Patient Arrival}

By Ambulance/Private Vehicle/Walk in

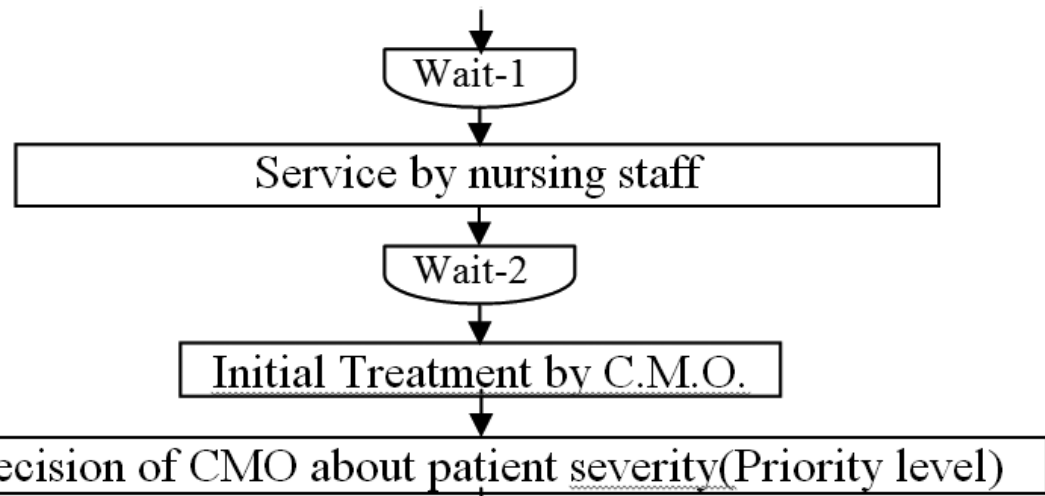

Decision of CMO about patient severity(Priority level)

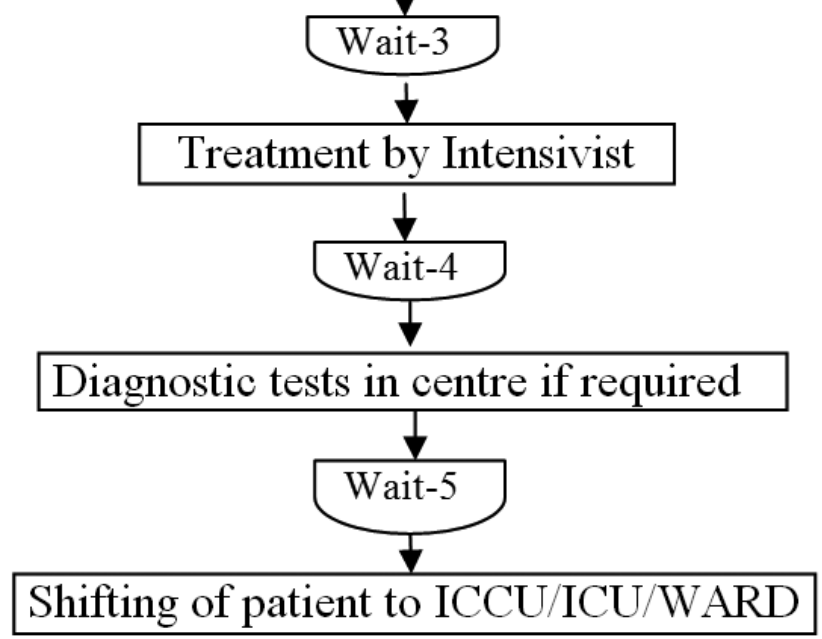

Fig. 1: Patient flow diagram 


\section{DISCUSSION}

From this study in "Role of time study in ED of an Indian hospital for quality health care," it was observed that some activities in the ED after the patient gets admitted are value added and some are non-value added. Value added activities are patient attending by nursing staff, patient attending and checking by $\mathrm{CMO}$, checking and treatment by intensivist, diagnostic procedure, and shifting of patient to ICCU/ICU/ ward.

Non-value-added activities include shifting of patient and waiting time for resources. Shifting of patient includes activities shifting of the patient from ambulance to bed in ED, shifting from ED to diagnostic center and again from diagnostic center to ED.

Such waiting times definitely affect scope for the life of the patient.

Who might be busy in another work like shifting of previous patient from casualty department to ICU/ICCU/ward or diagnostic center or was already sent with ambulance.

Various patients waiting times observed in our time study directly affect the patient satisfaction levels. They also unnecessarily engage or occupy the already scant number of beds in the casualty department which again hampers the patient arrival process in the casualty department. Waiting time for intensivist contributed a large portion of the time for the starting of treatment of intensivist. This waiting time is the most crucial time for the overall treatment and satisfaction of the patient. Waiting time for bed played key role in the LOS of the patient in ED before shifting of the patient to ICCU/ICU/ward. For every patient waiting for diagnostic tests did not appear, it happens when the diagnostic center is busy. It occurs due to the diagnostic procedure of patient admitted in ICCU or ICU. Hence, from above discussion, it is obvious that the waiting time for intensivist, bed in ICCU or ICU are important.

The delay in getting intensivists can be overcome by either appointing the full-time intensivists in rotation for $24 \mathrm{hrs}$ or by training the available CMOs for the emergency management of the patient. This delay can also be taken care by following standard operating procedures in ED where the protocols for different patients are developed and strictly followed. This can avoid the variation in the treatment.

The delay in getting ICCU/ICU beds can be solved by always keeping some beds in ICCU empty or by prompt discharge of the patients from ICCU if he or she no more needs intensive care. If the whole system is computerized like hospital information services, then the availability of beds in ICCU can be easily monitored by the CMO, and it will help him to manage the patine load immediately.

The delay in getting the diagnosis done can be solved by having the facilities like CT scan in the same campus or having a properly designed casualty set up. There also guidelines for construction of hospitals.

All these things can be better managed in the big government of private set up due to availability of manpower, but in small individual doctor hospital, it can be difficult to implement.

\section{Limitations}

There are some limitations of the time and motion study. The time and motion studies focus on the productive resources like the hospital staff and equipment. Traditionally, these techniques do not focus much on improving services. However, in hospitals, the level of services is very important. This disadvantage can easily be overcome by treating patients with specialized resources. This limitation can also be overcome by appropriately changing the focus of work study and design

\section{CONCLUSION}

The result of this time and motion study shows that after the entry of the patient in the ED, he or she is subjected to different kinds of waits such as for ward boy, intensivist, diagnostic tests, bed in ICCU or ICU or ward.

Out of this, wait for intensivist and for bed are very important for the overall treatment of the patient

The hospital should aim at reducing these waits by proper management. This study focuses scope for the improvements in patient waiting time which is the important contributor of the patient satisfaction.

\section{REFERENCES}

1. Kyriacou DN, Ricketts V, Dyne PL, McCollough MD, Talan DA. A 5-year time study analysis of emergency department patient care efficiency. Ann Emerg Med 1999;34(3):326-35.

2. Hendrich A, Chow MP, Skierczynski BA, Lu Z. A 36-hospital time and motion study: How do medical-surgical nurses spend their time? Perm J 2008;12(3):25-34

3. Saunders CE. Time study of patient movement through the emergency department: Sources of delay in relation to patient acuity. Ann Emerg Med 1987;16(11):1244-8.

4. Huang Q, Thind A, Dreyer JF, Zaric GS. The impact of delays to admission from the emergency department on inpatient outcomes. BMC Emerg Med 2010;10:16.

5. Worster A, Fernandes CM, Malcolmson C, Eva K, Simpson D. Identification of root causes for emergency diagnostic imaging delays at three Canadian hospitals. J Emerg Nurs 2006;32(4):276-80.

6. Qian SY, Yu P, Zhang ZY, Hailey DM, Davy PJ, Nelson MI. The work pattern of personal care workers in two Australian nursing homes: A time-motion study. BMC Health Serv Res 2012;12:305.

7. Gottschalk A, Flocke SA. Time spent in face-to-face patient care and work outside the examination room. Ann Fam Med 2005;3(6):488-93.

8. Weigl M, Müller A, Zupanc A, Angerer P. Participant observation of time allocation, direct patient contact and simultaneous activities in hospital physicians. BMC Health Serv Res 2009;9(1):110.

9. Paine S. A report of the findings of a 1-year study of the waiting times among patients attending an accident and emergency department. Accid Emerg Nurs 1994;2(3):130-3

10. Azzopardi M, Cauchi M, Cutajar K, Ellul R, Mallia-Azzopardi C, Grech V. A time and motion study of patients presenting at the accident and emergency department at Mater Dei Hospital. BMC Res Notes 2011;4:421.

11. Banerjea K, Carter AO. Waiting and interaction times for patients in a developing country accident and emergency department. Emerg Med J 2006;23(4):286-90.

12. Fromm RE Jr, Gibbs LR, McCallum WG, Niziol C, Babcock JC, Gueler AC, et al. Critical care in the emergency department: A timebased study. Crit Care Med 1993;21(7):970-6. 